\title{
EVALUACIÓN DE LA DISPOSICIÓN A PAGAR (DAP) POR ATRIBUTOS PARA VIVIENDAS ENERGÉTICAMENTE EFICIENTES. APROXIMACIONES PARA SU CALIFICACIÓN Y CERTIFICACIÓN ENERGÉTICA
}

\section{EVALUATION OF WILLIGNESS TO PAY (WTP) FOR ATTRIBUTES FOR ENERGY EFFICIENT DWELLINGS, APROACHES FOR YOUR QUALIFICATION AND ENERGY CERTIFICATION}

\author{
FITCH OSUNA, Jesús Manuel \\ Universidad Autónoma de Nuevo León (UANL) \\ Facultad de Arquitectura, \\ Profesor Titular \\ Av. Universidad, Ciudad Universitaria, San Nicolás de los Garza, N.L., México. \\ Email: jesus.fitchos@uanl.edu.mx \\ Teléfono: +52 8183294160 Extensión: 6790 \\ NARVÁEZ TIJERINA, Adolfo \\ Universidad Autónoma de Nuevo León (UANL) \\ Facultad de Arquitectura, \\ Profesor Titular \\ Av. Universidad, Ciudad Universitaria, San Nicolás de los Garza, N.L., México \\ Email: adolfonarvaez@gmail.com \\ Teléfono: +52 8183294160 Extensión: 6790 \\ MARMOLEJO DUARTE, Carlos \\ Centro de Política de Suelo y Valoraciones (CPSV) \\ Universidad Politécnica de Cataluña (UPC) \\ Profesor Titular de Unversidad \\ Av. Diagonal, 649, 08028 Barcelona \\ Email: carlos.marmolejo@upc.edu \\ Teléfono: +34934054385
}

Palabras claves: Mercado inmobiliario; valoración contingente; certificación energética; eficiencia energética

Key words: Real estate market; contingent valuation; energy certification; energy efficiency

\section{Resumen}

El ser humano a lo largo del tiempo ha buscado en la construcción de su hábitat satisfacer la necesidad de protección ante los elementos ambientales. Necesidad por la flexibilidad y la capacidad física que tiene a la adaptación, lo cual es relativamente débil comparada con la de otros seres vivos. Es por ello que la arquitectura ha creado el enfoque bioclimático, que persigue la eficiencia energética en los espacios, con el objetivo de ser autosuficientes y confortables gracias al aprovechamiento de los recursos naturales.

El diseño de la vivienda en la historia de la humanidad ha reflejado diversas soluciones adoptadas para ser construida de manera controlada e insertada en un ambiente natural, el cual es por lo general variable y adverso con el frío, el calor, el viento, las lluvias y el sol. Sin 
embargo, el crecimiento y aglomeración de la población a partir del siglo XX ha fomentado una serie de problemáticas derivadas por no atender la tarea de adaptar de una manera adecuada la vivienda al entorno. El factor biológico en el sitio y los criterios de diseño y construcción han dejado de lado la consideración de atributos que propician el confort térmico, como componente determinante en la definición de una vivienda eficiente energéticamente.

En el contexto institucional, se tiene más de una década en que la Unión Europea instauró en las viviendas, la obligación universal de Certificar la Eficiencia Energética (CEE) en el momento de su compra venta. Es así, que el mercado inmobiliario de Europa tiene una calificación institucionalizada para dar transparencia energética a las operaciones inmobiliarias y, sobre todo, incentivar la construcción/renovación de edificios eficientes. Sin embargo, no se han tenido los avances planeados y ha quedado como meras buenas intenciones.

En el contexto mexicano se han creado diversos programas para mejorar la eficiencia energética en la vivienda, tal es el caso de la hipoteca verde. No obstante, el resultado no ha sido el esperado. La investigación nace ante estas inquietudes, en donde se pretende conocer el impacto de la eficiencia energética en el valor de la vivienda.

Para ello se han establecido dos objetivos:

1) Analizar si los potenciales compradores de vivienda estarían dispuestos a pagar (DAP) más por viviendas energéticamente eficientes.

2) Saber si las unidades con las que se expresa la eficiencia energética inciden sobre la DAP.

El método empleado es el de valoración contingente, el cual consiste en simular un mercado hipotético mediante una encuesta a los consumidores potenciales. Se le ha preguntado por la máxima cantidad de dinero que están dispuestos a pagar por el bien si tuviera una serie de atributos ligados a la eficiencia térmica al compararlo. Razón por la cual se ha situado a la valoración contingente como un procedimiento razonable para medir la pérdida de utilidad en personas que no van a disfrutar de forma inmediata un bien singular, pero que estarían dispuestas a pagar algo por la opción de disfrutarlo en el futuro.

Entre los hallazgos obtenidos se tienen aproximaciones acerca del efecto de la eficiencia energética sobre las preferencias de las personas, y más particularmente sobre la disposición a pagar por las viviendas más eficientes. Se identifican confusiones en la manera de mesurar y la conceptualización de eficiencia energética. Adicionalmente las personas están dispuestas a realizar un pago adicional por la vivienda eficiente energéticamente, cabe señalar que relacionado al ahorro que se obtiene en la factura de gas y electricidad.

\section{Abstract}

The human being over time has sought in the construction of their habitat to satisfy the need for protection from environmental elements. Necessity for the flexibility and physical capacity that has adaptation, which is relatively weak compared to other living beings. That is why architecture has created the bioclimatic approach, which pursues energy efficiency in spaces, with the aim of being self-sufficient and comfortable thanks to the use of natural resources.

Citación: APELLIDO, N. et al. Titulo completo del artículo. En: Libro de proceedings, CTV 2018. XII Congreso Internacional Ciudad y Territorio Virtual. "Ciudades y Territorios Inteligentes". UNCuyo, Mendoza, 5-7 septiembre 2018. Barcelona: CPSV, 2018, p. 263-284. 
The design of the house in the history of humanity has reflected various solutions adopted to be constructed in a controlled manner and inserted in a natural environment, which is usually variable and adverse with the cold, heat, wind, rain and the sun. However, the growth and agglomeration of the population since the twentieth century has fostered a series of problems derived from not addressing the task of adapting housing in an adequate way to the environment. The biological factor in the site and the design and construction criteria have left aside the consideration of attributes that promote thermal comfort, as determinant components in the definition of an energy efficient house.

In the institutional context, there is more than a decade in which the European Union established in housing, the universal obligation to Certify Energy Efficiency (EEC) at the time of purchase sale. Thus, the European real estate market has an institutionalized rating to give energy transparency to real estate operations and, above all, encourage the construction / renovation of efficient buildings. However, the planned progress has not been made and has remained as mere good intentions.

In the Mexican context, several programs have been created to improve energy efficiency in housing, such as the green mortgage. However, the result has not been as expected. The research was born in response to these concerns, where the aim is to know the impact of energy efficiency on the value of housing.

For this, two objectives have been established:

1) Analyse if home buyers are willing to pay (DAP) more for energy efficient homes.

2) Know if the units with which energy efficiency is expressed affect the DAP.

The method used is contingent valuation, which consists of simulating a hypothetical market by means of a survey of potential consumers. He has been asked about the maximum amount of money they are willing to pay for the good if he had a series of attributes linked to thermal efficiency when comparing it. Reason why it has been placed to the contingent valuation as a reasonable procedure to measure the loss of utility in people who will not immediately enjoy a singular good, but who would be willing to pay something for the option to enjoy it in the future.

Among the findings obtained are approximations about the effect of energy efficiency on the preferences of people, and more particularly on the willingness to pay for the most efficient homes. Confusions are identified in the way of measuring and the conceptualization of energy efficiency. Additionally, people are willing to make an additional payment for energy efficient housing, it should be noted that related to the savings obtained in the gas and electricity bill.

\section{El precio inmobiliario y los Certificados de Eficiencia Energética (EPC). El valor de los atributos ambientales en la vivienda}

La arquitectura sustentable es la interacción de las edificaciones con el medio ambiente, por medio de energías alternas o dispersas en el medio ambiente. La arquitectura bioclimática busca que disminuya el impacto del uso de los recursos como energía eléctrica, el gas, el agua, entre otros. El diseño bioclimático da una respuesta que conforta al usuario en sus diferentes sentidos y además propicia eficiencia energética de la vivienda en su funcionamiento. Es decir, logra una comodidad óptima y sin consumir grandes cantidades de energía. Esto se puede ver reflejado en la investigación realizada por el Instituto de Ingeniería 
de la UNAM (Mejía, Morrillón y Rodríguez, 2001), que mediante el empleo combinado de protecciones solares se hace una disminución de las ganancias de calor.

Sin embargo, la falta de planeación en este ámbito ocasiona posteriormente costos energéticos, que involucra la instalación de equipo que mejore la operación del inmueble; además de un gasto energético para su óptimo funcionamiento. Si se considera la utilización del diseño bioclimático todos esos gastos se estarán recuperando durante la vida útil del inmueble y además promocionará la disminución de consumo de energía para obtener el confort deseado en el inmueble.

Fitch (2017) presenta un estudio, donde pone a discusión la dimensión ambiental, específicamente el confort térmico. La inquietud surge al indagar la disposición a pagar por disponer los inmuebles de este atributo, ya que el factor ambiental es circunstancial en nuestra forma de vida, y una buena definición del diseño arquitectónico propicia beneficios económicos en su operación.

Destaca que los formatos de las instituciones y entidades en el ramo de la valuación no comprenden algún apartado del cual se desarrolle un estudio del inmueble en donde se analicen las condiciones de confort. Establece que es necesario obtener un valor más ajustado a las características particulares del inmueble, tales como son su orientación, el tipo de material empleado, distancia entre piso y techo, dimensión de las ventanas y su orientación, y la utilización de elementos que propician la calidad térmica del inmueble (partesoles, aleros, entre otros). Esto conlleva a tener reflexiones sobre la situación en que se encuentra la vivienda en su contexto ambiental. A causa de una baja eficiencia bioclimática, el consumidor deberá realizar un gasto excedente para mejorar el confort térmico de la construcción, por la falta de planeación bajo estos principios. En consecuencia, se plantea la valuación económica de la vivienda hacia un sentido de habitabilidad; es decir, no solamente lo que constituye el principio económico (mayor y mejor uso), ya que el mercado en ocasiones no revela factores que derivan hacia un aumento del bienestar y con ello una mejora en la calidad de vida.

La disposición a pagar se puede ver reflejada en la elección de la vivienda, buscando además de los factores intrínsecos ( $\mathrm{m} 2$ de superficie, número de dormitorios y servicios sanitarios, entre otros factores que son propios del bien) factores como un buen nivel ambiental y de calidad urbana, espacios libres, bajas densidades, niveles bajos de congestión de tráfico y ruidos, buen nivel de dotación de servicios públicos, entre otros factores que acompañan al momento de asentarse las áreas residenciales. La serie de elementos que tiene la vivienda hace que se le denomine como un bien multiatributo. La acción individual de elección residencial conduce a formar una actuación agregada, en donde los usuarios urbanos se encuentran en función de su nivel de ingresos, edad, estado en el ciclo de vida familiar, nivel profesional, y aspectos económicos-sociales similares. El resultado es la configuración del territorio mediante áreas con una determinada demanda homogénea. Este proceso, conduce a poder interpretar el territorio desde una perspectiva de la formación y distribución espacial de valores urbanos, donde se busca entender cómo incide la calidad ambiental en el territorio.

En esta línea, García Almirall (1998) establece medidas indicativas del valor implícito de ciertas variables medioambientales, que vienen a internarse en los valores urbanos, utilizando el análisis estadístico multidimensional y técnicas de análisis espacial SIG. Constituyendo un primer paso clave en el desarrollo de modelos explicativos de la diferenciación y estructuración de los valores urbanos con una mayor integración de variables medioambientales urbanas. 
El valor como amenidad de cualquier configuración del medio ambiente viene determinado por las respuestas humanas que genera. Por lo tanto, el concepto de amenidades se relaciona con todo el sistema de variables estímulo-respuesta; con las condiciones que influyen en la aparición del estímulo: su intensidad, amplitud y duración; y con la significación de estos estímulos para los seres humanos expuestos a ellos.

El concepto de amenidades incluye componentes físicos y culturales, relacionados con una vida más conveniente. John Burchard (1965) ha relacionado la belleza urbana, incluyendo el clima y el cielo, los lagos, ríos, parques y plazas. Asimismo, ha catalogado jerárquicamente diversas ciudades del mundo en términos de una calificación en cuanto a amenidad urbana, basada en 24 características cualitativas, entre las cuales se encuentran: hermosos ríos y lagos, grandes parques, árboles y plantas, aire puro, clima generalmente benigno, edificios sobresalientes, museos de importancia, buenas bibliotecas, alrededores variados, pasado importante y arte en las calles.

La medida que se aplica a una amenidad se basa en la respuesta que despierta en los seres humanos, los valores, normas y gustos de la población. Deberán influir necesariamente en la caracterización, en cuanto a amenidades, de aquellas variables del medio ambiente que inciden en el espacio vital de la población puesto que las percepciones humanas son críticas para el concepto básico, las características de amenidad de una variable del medio ambiente, considera aisladamente en combinación con otras, pueden por tanto variar entre un grupo y otro de la población, de un lugar a otro y de una a otra fecha.

El papel que juegan las amenidades en la elección locacional tiene una importancia creciente puesto que unas rentas reales generalmente crecientes y unos mejores servicios de transporte rompen con la importancia de los lazos con el lugar de trabajo, para todos los grupos, excepto los de menores rentas. Por lo tanto, las ventajas en cuanto a situación y microclima tienen una significación creciente. Constituyen "nuevos recursos" puesto que, con una mayor demanda de ellos, su valor es superior.

Krumm (1980) establece un modelo de equilibrio espacial de mercado residencial, integra características de vivienda y constata que aquellos factores son especialmente de homogeneidad del barrio y del nivel de servicio.

\section{El impacto de las etiquetas EPC sobre el precio de los inmuebles}

La aparición de las etiquetas energéticas, derivadas de los EPC de la Unión europea, es bastante reciente en relación con la consolidada tradición derivada del conjunto de certificaciones previas afiliadas a la «industria verde» de la calificación edilicia. En efecto, los estudios empíricos se han centrado en el estudio del impacto sobre los precios de oferta de etiquetas, como la británica BREEAM, la francesa HQE, la helvética Minergie o las americanas LEED y Energy Star. En esta sección se ofrece una revisión de dichos estudios internacionales, así como de los más escasos centrados en las comunitarias EPC.

Desde una perspectiva metodológica, el análisis del sobrevalor que supone una eventual mejora en el nivel de bienestar (p.e. beneficiarse de una vivienda energéticamente cualificada) pasa por analizar la formación de precios. La mayor parte de los estudios ha acudido a la técnica de los precios hedónicos afiliada a la familia de las preferencias observadas. Aplicada 
al mercado residencial, dicha técnica asume que el valor de una vivienda puede descomponerse en diferentes partes atribuibles a sus características arquitectónicas y urbanas. Así, con el concurso de métodos econométricos, encuentra los precios implícitos de dichas características (Fitch 2006).

En esta línea, el trabajo de Dinan \& Miranowski (1989) realizado en el mercado residencial de lowa (EEUU) comprobó, por vez primera, la relación de directa proporcionalidad entre los precios inmobiliarios y la eficiencia energética. Así, las mejoras introducidas equivalentes a una reducción de un USD en el consumo energético de refrigeración, para un nivel de confort determinado, se convirtieron en un market premium de 11.63 USD en el precio de venta. ¿Guardan relación los certificados energéticos con los precios? Hasta el año 2013, cuando la refundación de la EPBD se traspuso en España, había 22 estudios publicados ( 3 en Europa) sobre la relación entre la certificación energética y los precios inmobiliarios. La mayor parte refiere edificios de oficinas. Así, en los EE UU el sobreprecio por el certificado LEED en edificios de oficina va desde cero en el estudio de Eichholtz et al. (2010), hasta un $25 \%$ en los de Fuerst \& McAllister (2011a y 2011b). Para el Energy Star, va de 5.8\% del estudio de Miller et al. (2008) hasta un 26\% del estudio de Fuerst \& McAllister (2015).

Para el mercado residencial, ninguno de los estudios revisados sobre el impacto de las etiquetas no-EPC reporta sobrevalores superiores al 10\%; de ellos, resulta interesante el hallazgo de Salvi et al. (2010) porque pone de relieve que el impacto es el doble en viviendas unifamiliares en relación con los apartamentos, siendo esta relación coherente con el hecho de que en las primeras la factura energética es muy superior que en los segundos. De nuevo, el único estudio publicado con precios de alquiler residencial vuelve a situar el impacto de la calificación energética en alquiler por debajo del encontrado en operaciones de compraventa. Finalmente, indicar que la relativa abundancia de estudios en el mercado no residencial pone de relieve la mayor difusión de los certificados (especialmente en EE UU) y la mayor transparencia/facilidad en el acceso a los datos necesarios para su estudio. $Y$, por ende, se destaca la necesidad de reforzar el estudio del mercado residencial.

La tabla 1 resume los resultados del principal programa empírico EPC-precios encargado por la CE (que no incluye a España). Como se ve, el impacto de un escalón de los EPC sobre los precios de oferta/cierre en venta es variopinto, y va desde sólo un $0.4 \%$ en Oxford hasta un $11 \%$ en Viena. Asimismo, se observa que en las ciudades la incidencia de la calificación sobre los precios es menor que en los hinterland (a excepción de Austria), lo cual sugiere que este efecto interactúa con los precios base de las viviendas. Así, en los sitios donde estos precios son menores, el impacto es proporcionalmente mayor y viceversa.

Al igual que lo que pasa con otro tipo de etiquetas verdes, el impacto sobre los precios de alquiler es mucho más modesto. Sin embargo, no siempre una mayor calificación energética implica un market premium, puesto que en el mercado de alquiler de Oxford existe aparentemente una penalización por las viviendas mejor calificadas (-4\% por escalón EPC). Aunque los autores de este trabajo reconocen las enormes deficiencias de sus análisis, puesto que, en dicha ciudad, las viviendas señoriales más antiguas y mejor localizadas, con precios elevados, tienen a su vez, una baja calificación energética. En general, el muy pobre control de las características urbanísticas (p.e. accesibilidad, calidad de la urbanización y jerarquía social) con incidencia sobre los valores residenciales, según lo ha estudiado Roca (1988), es una deficiencia de dicho trabajo y puede sesgar los coeficientes de sus modelos.

Citación: APELLIDO, N. et al. Titulo completo del artículo. En: Libro de proceedings, CTV 2018. XII Congreso Internacional Ciudad y Territorio Virtual. "Ciudades y Territorios Inteligentes". UNCuyo, Mendoza, 5-7 septiembre 2018. Barcelona: CPSV, 2018, p. 263-284. 
Tabla 1. Efecto de los EPC sobre los precios de venta y alquiler en diez ciudades europeas, según el estudio encargado por la CE

\begin{tabular}{lcccc}
\hline Casos de estudio & \multicolumn{2}{c}{ Impacto de los EPC en } & $\begin{array}{c}\text { Tipo precios en los } \\
\text { modelos de venta }\end{array}$ & $\begin{array}{c}\text { Fuente de los datos usados en los } \\
\text { modelos de precios hedónicos }\end{array}$ \\
\hline Viena & Precios/Valores venta & Alquileres & Portal inmobiliario \\
\hline Baja Austria & Entre el 10\% y 11\% & Entre el 5\% y el $6 \%$ & Oferta & Portal inmobiliario \\
\hline Bruselas (Flandes) & Entre el 5\% y el $6 \%$ & $4,40 \%$ & Oferta & Portal inmobiliario \\
\hline Bruselas (Capital) & $4,30 \%$ & $3,20 \%$ & Oferta & Portal inmobiliario \\
\hline Bruselas (Wallonia) & $2,90 \%$ & $2,60 \%$ & Oferta & Portal inmobiliario \\
\hline Lille & $5,40 \%$ & $1,50 \%$ & Oferta & Notarios \\
\hline Marsella & $3,20 \%$ & nd & Cierre & Notarios \\
\hline Ciudades de Irlanda & $4.3 \%$ & nd & Oferta & Portal inmobiliario \\
\hline Irlanda no ciudades & $1,70 \%$ & $1,40 \%$ & Oferta & Portal inmobiliario \\
\hline UK (Oxford Sur UK) & $3,80 \%$ & $1,40 \%$ & Oferta & Portal inmobiliario \\
\hline
\end{tabular}

Fuente: Elaboración propia sobre los datos de Mugdal et al. (2013)

Otros estudios no han encontrado una relación lineal ni continua entre la calificación EPC y los precios. Pontus et al. (2014) concluyeron que, en las viviendas suecas situadas en el cuartil inferior de precios, la correlación entre eficiencia energética y precio es negativa; es decir, a mayor eficiencia, menor precio. Asimismo, en el segmento superior de viviendas más caras la eficiencia energética resultó ser no significativa. Hyland et al. (2013) encuentran, en Irlanda, que el impacto de un escalón de la EPC en un apartamento de dos habitaciones equivale a un incremento del $2.3 \%$, mientras que en las viviendas de tres habitaciones y 4-5 habitaciones el incremento es menor y se sitúa en el $1.7 \%$ y $1.6 \%$, respectivamente. Fuerst et al. (2015), a partir del estudio de 300 mil viviendas en Inglaterra, han encontrado que el mayor impacto de la EPC se produce en las casas adosadas, y que en los apartamentos es mayor que en las casas aisladas. Lo que podría sugerir varias cosas, entre otras, que el ahorro potencial en los consumos es más importante para las viviendas más baratas ocupadas por personas de menor nivel de renta.

Como se ve, hay una gran divergencia en el impacto de los EPC sobre los valores residenciales a lo largo de Europa, explicada por las importantes diferencias en términos de renta, costes energéticos, exigencias/técnicas constructivas, climáticas y, quizá, de valoración de la importancia de la preservación del medio ambiente. Además, como lo han estudiado GarcíaHoggius y Neila (2013), la forma en cómo ha sido transpuesta la Directiva, utilizando formas de cálculo divergentes, muchas veces apoyadas en normativas estatales previas, complica las comparaciones transfronterizas.

En España, dos son los trabajos pioneros en la cuantificación de la agenda hedónica de las etiquetas EPC. De Ayala et al. (2016), parte de valores de venta declarados por una muestra de encuestados de cinco ciudades (Madrid, Bilbao, Sevilla, Vitoria y Málaga), y de un cálculo propio de la calificación energética y determinan que las viviendas calificables como A, B o C tienen un valor, en opinión de sus propietarios, superior en un $9.8 \%$ que las calificadas como $D$, E, F o G. Por su lado, Marmolejo (2016) utiliza valores de oferta para una muestra de viviendas en venta en Barcelona y encuentra un sobreprecio de $5.11 \%$ por pasar de la calificación $G$ a la $\mathrm{A}$, o del $9.62 \%$ si aceptamos que las personas perciben que la escala de calificaciones es nominal.

Citación: APELLIDO, N. et al. Titulo completo del artículo. En: Libro de proceedings, CTV 2018. XII Congreso Internacional Ciudad y Territorio Virtual. "Ciudades y Territorios Inteligentes". UNCuyo, Mendoza, 5-7 septiembre 2018. Barcelona: CPSV, 2018, p. 263-284. 


\section{La regulación e implantación de los certificados energéticos en México}

La cultura de ahorro de energía en México se inició hace más de una década, sin embargo, el efecto aún no es claro. Es necesario ver diseños de viviendas que se adapten a las necesidades de la sociedad mexicana y que las tecnologías empleadas se vean mejoradas por su alto consumo de energía, sin repercutir el valor de la vivienda para su adquisición.

En materia legal, La Constitución Política de México establece en su artículo 4ํㅣos elementos para salvaguardar los derechos humanos de los mexicanos respecto a la vida digna, a la salud, al agua, al medio ambiente sano y a la vivienda adecuada. Las regulaciones sobre la construcción de viviendas que sean más eficientes energéticamente, cómodas y que contribuyan a que la vida humana se desarrolle con dignidad, tienen su sustento en este mandato de nuestra carta magna.

En tanto que los artículos 25, 27 y 28 de la Constitución mexicana señalan la necesidad de regular, en el sentido de lograr equidad social, contar con los medios para lograr el desarrollo industrial sustentable, garantizando el cuidado y conservación del medio ambiente.

Los temas legislativos que se derivan de estos principios fundamentales apuntan hacia varios objetivos prioritarios del desarrollo de nuestra sociedad, en tanto que de éstos se desprenden reglamentos sectoriales encaminados al control de las acciones que los diversos actores del país llevan a cabo. El árbol legislativo que se desprende de estos principios fundamentales intenta abarcar las áreas de las actividades humanas que podrían generar conflicto a estos grandes principios y es abundante.

Si se hiciera el análisis de los diversos niveles legislativos que desembocan en la regulación sobre el gasto energético de las viviendas, diríamos que en el nivel de las leyes en la materia podríamos señalar la Ley de Transición energética como el fundamento de aquél, y del cual se deriva en el nivel de los reglamentos el Reglamento de la Ley de Transición Energética, que fundamenta al Plan Nacional de Desarrollo. Este último, como fundamento de todas las políticas de gobierno, se instrumenta a través de una serie de estrategias. Las dos estrategias en la materia que darían origen a la regulación sobre los certificados serían la Estrategia Nacional de Cambio Climático y la Estrategia de Transición para Promover el Uso de Tecnologías y Combustibles más Limpios. La primera, de más amplios alcances, y la segunda, mayormente encaminada a la generación de energía, el transporte y la producción de materiales que contribuyan a sostener el desarrollo con una demanda sostenible de recursos.

De los programas que se derivan de ambas estrategias el que se relaciona más directamente con la necesidad de generar certificados energéticos en México sería el Programa Nacional de Aprovechamiento Sustentable de la Energía, del que se desprenden los lineamientos y normas de la familia denominada «Establecimiento de criterios normativos en Energías Limpias, Eficiencia Energética, Cogeneración Eficiente, Sistemas de Generación limpia distribuida, Emisión de Gases y Compuestos de Efecto Invernadero».

De esta familia de normas es que se deriva la NORMA Oficial Mexicana NOM-020-ENER-2011, Eficiencia energética en edificaciones. Envolvente de edificios para uso habitacional. Esta norma es uno de los principales instrumentos para calcular la ganancia de calor de la envolvente y a partir de ello calificar la vivienda. Esto se basa en el hecho de que la mayor

Citación: APELLIDO, N. et al. Titulo completo del artículo. En: Libro de proceedings, CTV 2018. XII Congreso Internacional Ciudad y Territorio Virtual. "Ciudades y Territorios Inteligentes". UNCuyo, Mendoza, 5-7 septiembre 2018. Barcelona: CPSV, 2018, p. 263-284. 
ganancia de energía en la vivienda se da por la exposición a la radiación solar, de lo que se deriva lógicamente que un adecuado diseño de la envolvente garantizará un uso más eficiente de los sistemas de enfriamiento, logrando tener un adecuado confort de sus habitantes con un uso menor de energía.

La NOM-020-ENER-2011 es un sistema de cálculo para conocer las características de forma de la envolvente, materiales y elementos termoaislantes para techos, plafones y muros de la edificación habitacional. La norma tiene un carácter obligatorio y se sanciona de acuerdo con lo dispuesto en la Ley Nacional sobre Metrología y Normalización y otras leyes aplicables.

La aplicación de la norma está garantizada por el uso de una etiqueta que debe colocarse en la vivienda en un lugar visible y no ser removida. En la etiqueta se certifica el consumo estimado de la vivienda para llevarla a un nivel de confort. En la parte superior de la misma, en una primera sección, se establece que la eficiencia energética está medida en función de la ganancia de calor, según el criterio expresado en la norma. Bajo este encabezado se encuentran los datos de ubicación de la vivienda en una segunda sección. En la tercera sección se ubican dos valores: arriba el de referencia que se basa en una vivienda ideal dadas unas condiciones idénticas de localización y orientación y abajo el de la vivienda real. Ambos valores son comparados en la cuarta sección que en forma gráfica muestra el porcentaje de ahorro del edificio respecto al ideal de la norma.

Abajo, en la quinta sección se muestran los datos de la fecha de etiquetado y del perito verificador, y en la sexta sección se añade una nota técnica para entender que el cumplimiento de la norma está en un ahorro de $0 \%$, es decir, cuando el valor del ahorro del edificio real es igual al de referencia.

A continuación, se enlistan en orden cronológico de su promulgación algunas normas mexicanas relacionadas con el ahorro de energía y el etiquetado.

Tabla 2. Normas oficinales en México relacionadas con la eficiencia y las etiquetas energéticas

\begin{tabular}{ll}
\hline Norma Oficial Mexicana & Descripción \\
\hline NOM-009-ENER-1995 & Eficiencia energética en aislamientos térmicos industriales \\
\hline NOM-006-ENER-1995 & Eficiencia energética electromecánica en sistemas de bombeo para \\
& pozo profundo en operación. Límites y método de prueba \\
\hline NOM-018-ENER-1997 & Aislantes térmicos para edificaciones. Características, límites y \\
& métodos de prueba \\
\hline NOM-001-ENER-2000 & Eficiencia energética de bombas verticales tipo turbina con motor \\
& externo eléctrico vertical. Límites y método de prueba \\
\hline NOM-008-ENER-2001 & Eficiencia energética en edificaciones, envolvente de edificios no \\
& residenciales \\
\hline NOM-015-ENER-2002 & Eficiencia energética de refrigeradores y congeladores \\
& electrodomésticos. Límites, métodos de prueba y etiquetado \\
\hline NOM-007-ENER-2004 & Eficiencia energética en sistemas de alumbrado en edificios no \\
& residenciales \\
\hline NOM-010-ENER-2004 & Eficiencia energética del conjunto motor bomba sumergible tipo pozo \\
& profundo Límites y método de prueba \\
\hline
\end{tabular}




\begin{tabular}{|c|c|}
\hline NOM-013-ENER-2004 & $\begin{array}{l}\text { Eficiencia energética para sistemas de alumbrado en vialidades y áreas } \\
\text { exteriores públicas }\end{array}$ \\
\hline NOM-014-ENER-2004 & $\begin{array}{l}\text { Eficiencia energética de motores de corriente alterna, monofásicos, de } \\
\text { inducción, tipo jaula de ardilla, enfriados con aire, en potencia nominal } \\
\text { de } 0.180 \text { a } 1500 \mathrm{kw} \text { Límites, método de prueba y marcado }\end{array}$ \\
\hline NOM-011-ENER-2006 & $\begin{array}{l}\text { Eficiencia energética en acondicionadores de aire tipo central, paquete } \\
\text { o dividido Límites, métodos de prueba y etiquetado }\end{array}$ \\
\hline NOM-004-ENER-2008 & $\begin{array}{l}\text { Eficiencia energética de bombas y conjunto motor-bomba, para } \\
\text { bombeo de agua limpia, en potencias de } 0.187 \mathrm{kw} \text { a } 0.746 \mathrm{kw} \text {. Límites, } \\
\text { métodos de prueba y etiquetado }\end{array}$ \\
\hline NOM-019-ENER-2009 & $\begin{array}{l}\text { Eficiencia térmica y eléctrica de máquinas tortilladoras mecanizadas. } \\
\text { Límites, método de prueba y marcado }\end{array}$ \\
\hline NOM-005-ENER-2010 & $\begin{array}{l}\text { Eficiencia energética de lavadoras de ropa electrodomésticas. Límites, } \\
\text { método de prueba y etiquetado }\end{array}$ \\
\hline NOM-016-ENER-2010 & $\begin{array}{l}\text { Eficiencia energética de motores de corriente alterna, trifásicos, de } \\
\text { inducción, tipo jaula de ardilla, en potencia nominal de } 0.746 \text { a } 373 \mathrm{kw} \text {. } \\
\text { Límites, método de prueba y marcado }\end{array}$ \\
\hline NOM-023-ENER-2010 & $\begin{array}{l}\text { E ciencia energética en acondicionadores de aire tipo dividido, } \\
\text { descarga libre y sin conductos de aire. Límites, método de prueba y } \\
\text { etiquetado }\end{array}$ \\
\hline NOM-028-ENER-2010 & $\begin{array}{l}\text { E ciencia energética de lámparas para uso general. Límites y métodos } \\
\text { de prueba }\end{array}$ \\
\hline NOM-020-ENER-2011 & $\begin{array}{l}\text { Eficiencia energética en edificaciones. Envolvente de edificios para uso } \\
\text { habitacional }\end{array}$ \\
\hline NOM-003-ENER-2011 & $\begin{array}{l}\text { Eficiencia térmica de calentadores de agua para uso doméstico y } \\
\text { comercial. Límites, método de prueba y etiquetado }\end{array}$ \\
\hline NOM-017-ENER/SCFI-2008 & $\begin{array}{l}\text { Eficiencia energética y requisitos de seguridad de lámparas } \\
\text { fluorescentes compactas auto-balastradas. Límites y métodos de } \\
\text { prueba }\end{array}$ \\
\hline NOM-021-ENER/SCFI-2008 & $\begin{array}{l}\text { Eficiencia energética, requisitos de seguridad al usuario en } \\
\text { acondicionadores de aire tipo cuarto. Límites, métodos de prueba y } \\
\text { etiquetado }\end{array}$ \\
\hline NOM-022-ENER/SCFI-2008 & $\begin{array}{l}\text { Eficiencia energética y requisitos de seguridad al usuario para aparatos } \\
\text { de refrigeración comercial auto-contenidos. Límites, métodos de prueba } \\
\text { y etiquetado }\end{array}$ \\
\hline NOM-020-ENER-2011 & $\begin{array}{l}\text { Se modifican los valores de coeficiente global de transferencia de calor } \\
\text { (K) de la tabla 1, se agregan definiciones y se acota la verificación de la } \\
\text { Norma Oficial Mexicana NOM-020-ENER-2011 }\end{array}$ \\
\hline
\end{tabular}

Fuente: Elaboración propia, a partir de Fundación IDEA (sin fecha), p.15.

El Uso eficiente de la energía en la vivienda en México se propone en la guía de la CONAFOVI (2006), mediante el empleo del diseño bioclimático. Algunos de los objetivos que se plantean son:

- Examinar áreas con potencial de ahorro y uso eficiente de energéticos y de recursos renovables y explorar las posibles implicaciones sobre el desarrollo del sector vivienda.

- Estudiar y discutir los impactos ambientales que provoca, directa e indirectamente el consumo de energía en las viviendas. 
- Crear enfoques más integrales del sector vivienda, lo que implica estudiar conjuntamente la oferta de combustibles, la demanda de energía por uso final en el sector, la influencia de los estilos de vida y las interacciones entre clima y vivienda, entre otros factores.

Las bases de las propuestas son consideradas por Sheinbaum (1996) y Morillón (2005). También señala que una de las políticas energéticas que más éxito ha tenido en otros países han sido la regulación en el aislamiento de las nuevas construcciones.

\section{Metodología, datos y caso de estudio}

El método empleado es el de Valoración Contingente (VC), permite entre otras cosas extraer la Disposición A Pagar (DAP) por beneficiarse de un cambio o Disposición A ser Compensado (DAC) por perjudicarse de un cambio de bienestar (Soguel, 1996). A través de simular un mercado hipotético mediante una encuesta a los consumidores potenciales (Mitchell y Carson, 1989). Se le ha preguntado por la máxima cantidad de dinero que están dispuestos a pagar por el bien si tuviera una serie de atributos ligados a la eficiencia térmica al compararlo, manteniendo el resto de atributos arquitectónicos y locativos invariables. Dichas variaciones se miden en unidades monetarias que mensuran las pérdidas/ganancias de bienestar de los encuestados ante el cambio ofrecido (Riera, 1994). Razón por la cual se ha situado a la VC como un procedimiento razonable para medir la pérdida de utilidad en personas que no van a disfrutar de forma inmediata un bien singular, pero que estarían dispuestas a pagar algo por la opción de disfrutarlo en el futuro, aun cuando las viviendas energéticamente eficientes son escasas en México.

La mejora al bienestar evaluado en los usuarios de la vivienda consiste en la mejora de la calificación energética de una vivienda convencional medianera de tres habitaciones, dos baños, con una superficie de unos $80 \mathrm{~m}^{2}$ útiles ubicado en el Área Metropolitana de Monterrey. Estas características corresponderían a la de la vivienda de interés medio y medio bajo. ${ }^{1}$

En concreto, la mejora de calificación energética ofrecida representa pasar de la clase energética $E$ a la $A$. Es decir, una mejora significativa de la eficiencia energética de las viviendas.

Para ilustrar las repercusiones sobre la economía familiar y el medio ambiente, las personas encuestadas fueron informadas del ahorro en la factura energética (gas y electricidad) y las emisiones de $\mathrm{CO}_{2}$ que supone la mejora en la eficiencia energética ofrecida. Además, con el objeto de producir decisiones bien informadas, las repercusiones económicas y ambientales de la mejora de la eficiencia energética fueron expresadas en unidades fácilmente comprensibles por el grueso de la población:

- El ahorro en la factura energética se expresó en pesos mensuales, es decir, en unidades monetarias expresadas en el periodo de pago habitual.

- Las emisiones de $\mathrm{CO}_{2}$ se expresaron en unidades de masa y en kilómetros que recorre un carro familiar.

Así, los participantes de la encuesta ${ }^{2}$ fueron informados que para la vivienda en cuestión pasar de la clase $E$ a la A supondría un ahorro de $\$ 650$ pesos/mes en las facturas de electricidad y gas, y una reducción de $\mathrm{CO}_{2}$ equivalente $16000 \mathrm{~km}$ de recorrido de un automóvil familiar.

\footnotetext{
1 El rango de los segmentos oscila de $\$ 639,664$ a $\$ 1,599,156$ pesos.

2 Se utilizó para su aplicación: Encuestas online. La cual es una plataforma que nos permite crear encuestas en línea, su interfaz simple nos ayuda a crear un cuestionario con una gran variedad de tipos de preguntas (si / no, abiertas, cerradas, clasificación, tabla / Matriz, etc.), integrando datos externos al cuestionario, añadiendo imágenes, archivos y mucho más. Cuando la encuesta esta lista genera un enlace en un sitio web, el cual se puede distribuir en las diferentes redes sociales, correo electrónico o enviar invitaciones. Puede ser llenada desde cualquier navegador y/o dispositivo electrónico.
} 
Estos ahorros son estimativos, y se han empleado criterios similares a los utilizados por Marmolejo y Bravi (2017) y, en cualquier caso, pueden variar en función de las condiciones climáticas y hábitos de uso de la vivienda.

Después de haber informado a las personas sobre las repercusiones económicas y ambientales de la mejora energética, se les preguntó directamente si estaban DAP más por el alquiler o la cuota mensual de la hipoteca de la vivienda $A$, teniendo en consideración sus posibilidades económicas. El formato de respuesta fue abierto, si bien se partió de un valor guía que coincide con el ahorro potencial en la factura energética. Así, en el primer tanteo se preguntó si se estaba DAP más o menos de 600 pesos, y en el segundo se pidió que se indicase de forma libre la cantidad exacta. Desde el primer momento, las personas también fueron informadas que podían estar no dispuestas a pagar.

Asimismo, se indagaron las razones detrás de la DAP o su rechazo; esta información permite conocer, en el caso de las personas que sí declararon estar DAP, si dicho sobrepago deriva de ahorros potenciales, de una conciencia en la preservación del ambiente/la salud pública o, incluso, de una eventual recompensa psicológica derivada de un consumo responsable.

La valoración contingente propiamente dicha se realizó dentro de una encuesta estructurada más amplia formada por tres partes:

1) Contextualización. Que indaga el conocimiento previo de las etiquetas energéticas en México, así como los hábitos energéticos y la satisfacción «energética» de la vivienda actual.

2) Valoración contingente. Se preguntó directamente a los encuestados por su DAP por la mejora en la calificación energética ofrecida. Para ello, se aclaró que el resto de características de la vivienda, así como su ubicación, permanecían sin cambios.

3) Perfil socio residencial. Que recoge información sociodemográfica y de la vivienda actual de las personas encuestadas.

Las encuestas informatizadas se hicieron en la primavera de 2017 a personas mayores de 18 años residentes en el área metropolitana de Monterrey que fueran inquilinas o propietarias de vivienda. Además, se indicó que por cada hogar la encuesta fuese respondida por una persona que participase en la toma de decisiones de la vivienda, incluida la elección residencial y que estuviese al tanto de las cuestiones financieras, incluso el pago de los servicios domiciliarios. En total, se cuenta con información de 276 participantes. Para ello se crea una base datos (xls).

El análisis de respuestas o resultados se pueden ver en tiempo real con informes agregados para cada pregunta como los son: diagramas, cifras claves, porcentajes, medias aritméticas, etc. Además, nos da la posibilidad de comprobar respuestas individualmente, filtrar resultados, hacer tabulaciones o descargar informes completos en programas como Word, PPT, Excel.

\section{Análisis de resultados}

¿Cuánto estamos dispuestos a pagar por tener una mejor calidad de vida?, así es, no solo considerar el ahorro de dinero en el pago de facturas, sino una mejora en el estilo de vida. Una vivienda sustentable, no es solo la que ahorra agua y luz, sino la que brinda un mejor bienestar social a sus usuarios mediante servicios cercanos, escuelas, parques, sistemas de ahorro de

Citación: APELLIDO, N. et al. Titulo completo del artículo. En: Libro de proceedings, CTV 2018. XII Congreso Internacional Ciudad y Territorio Virtual. "Ciudades y Territorios Inteligentes". UNCuyo, Mendoza, 5-7 septiembre 2018. Barcelona: CPSV, 2018, p. 263-284. 
energía, agua, gas, etc. Probablemente los encuestados no dirían que "pagaría más sólo por hacerle un bien al medio ambiente" por lo general se busca un beneficio, una compensación.

Los resultados de los hábitos sostenibles de las personas encuestadas, se reflejan en la tabla 3 , donde el principal comportamiento sostenible es el ahorro de energía en el ámbito doméstico, seguido por la reutilización del agua pluvial y finalmente el reciclaje de basura. En relación con este último aspecto, es comprensible que haya sido el menos frecuente, lo que responde al hecho de que a lo largo del espacio metropolitano de Monterrey no se dispone siempre de contenedores de basura separados, y cuando los hay éstos responden a una política de reciente implementación. En todo caso, los resultados sugieren que en cierta medida las personas son conscientes de que tanto el gasto energético e hídrico es un elemento importante.

\section{Tabla 3. Hábitos sostenibles de las personas encuestadas}

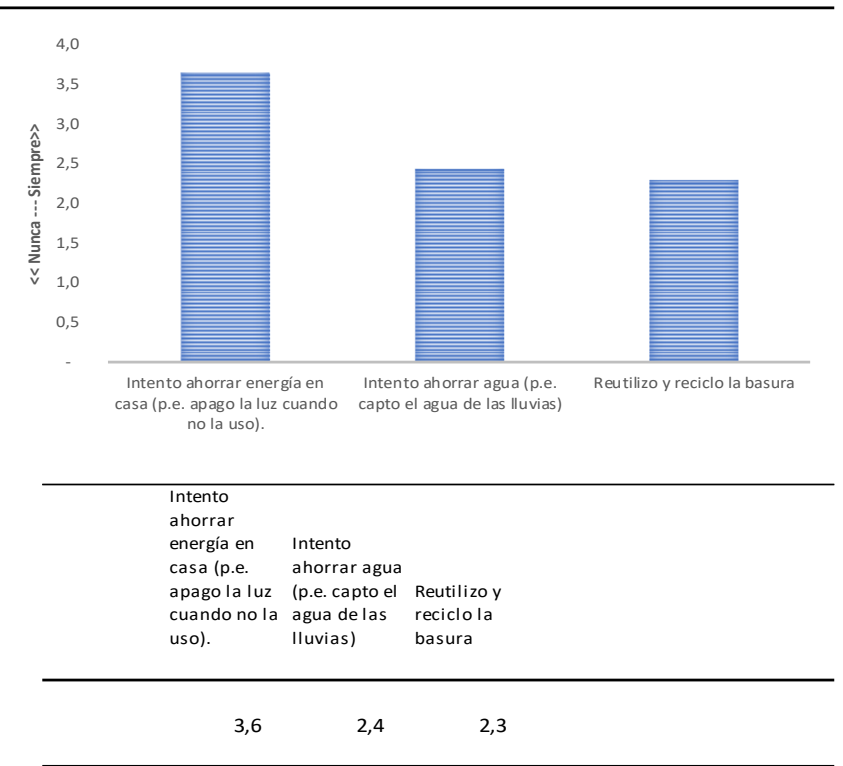

1 = nunca, 4 = siempre

Fuente: Elaboración propia

El $68 \%$ de las personas dijo conocer la etiqueta energética implementada en México para medir la eficiencia energética de las viviendas. Sin embargo, con el objeto de indagar el nivel de conocimiento de las personas encuestadas sobre las etiquetas energéticas, se les preguntó si creían que éstas sólo indagaban sobre la eficiencia energética o, por el contrario, también median la calidad y los materiales y equipos.

La tabla 4 documenta que la mayor parte $(76 \%)$ de las personas encuestadas erran al confundir el significado de las etiquetas energéticas, al creer que éstas son un indicador global de la calidad de los edificios. Por tanto, a pesar de que las personas dicen conocer una mayor proporción de las etiquetas energéticas, como se ve, no acaban de entender exactamente cuál es su significado. Esto sugiere la necesidad de que las autoridades competentes sumen esfuerzos con tal de concienciar e instruir a las personas sobre lo que se mide en una etiqueta energética y cómo se hace.

Citación: APELLIDO, N. et al. Titulo completo del artículo. En: Libro de proceedings, CTV 2018. XII Congreso Internacional Ciudad y Territorio Virtual. "Ciudades y Territorios Inteligentes". UNCuyo, Mendoza, 5-7 septiembre 2018. Barcelona: CPSV, 2018, p. 263-284. 
Tabla 4. Nivel de conocimiento de las etiquetas energéticas

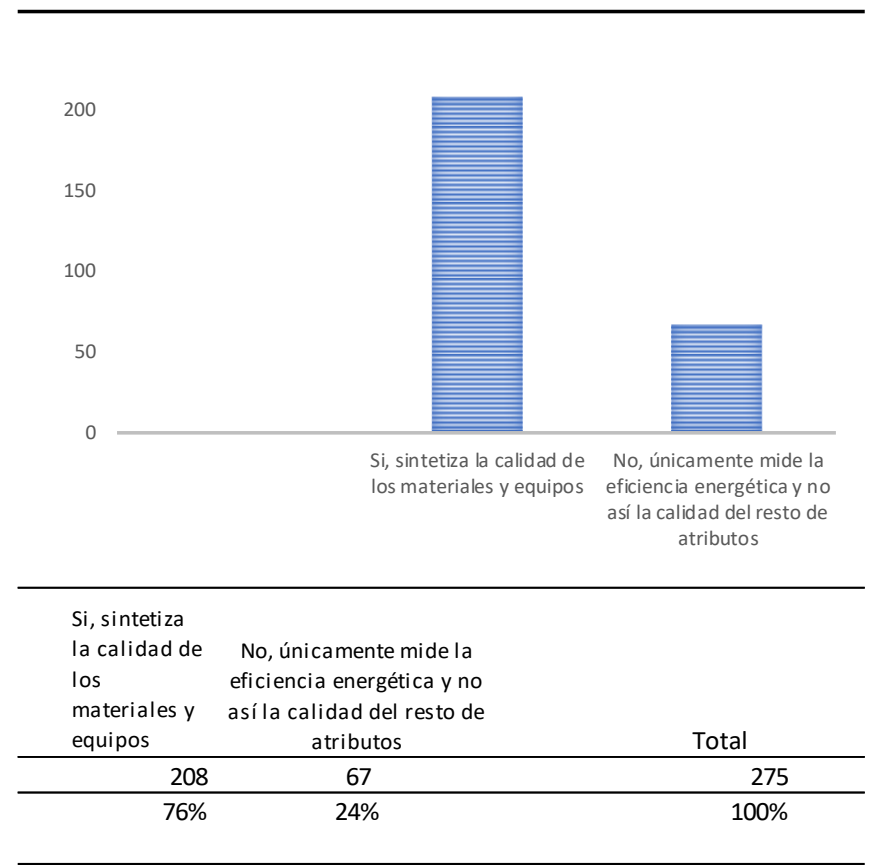

Fuente: Elaboración propia

En el mismo sentido anterior, se han indagado los cambios en el comportamiento de las personas en relación con la eficiencia energética en el evento de que cambiasen de su vivienda actual a una más eficiente. La tabla inferior sugiere que la mayor parte de las personas $(60 \%)$ se preocuparían más por el gasto energético, cuando lo previsible es que se preocupara menos, puesto que una vivienda más eficiente permite alcanzar las condiciones térmicas y lumínicas de confort con un menor gasto energético, lo cual refrenda las conclusiones anteriores; es decir, las personas no tienen claro lo que es la eficiencia energética.

\section{Tabla 5. Cambios declarados en los hábitos de consumo energético en el evento de que se cambiase a una vivienda más eficiente}

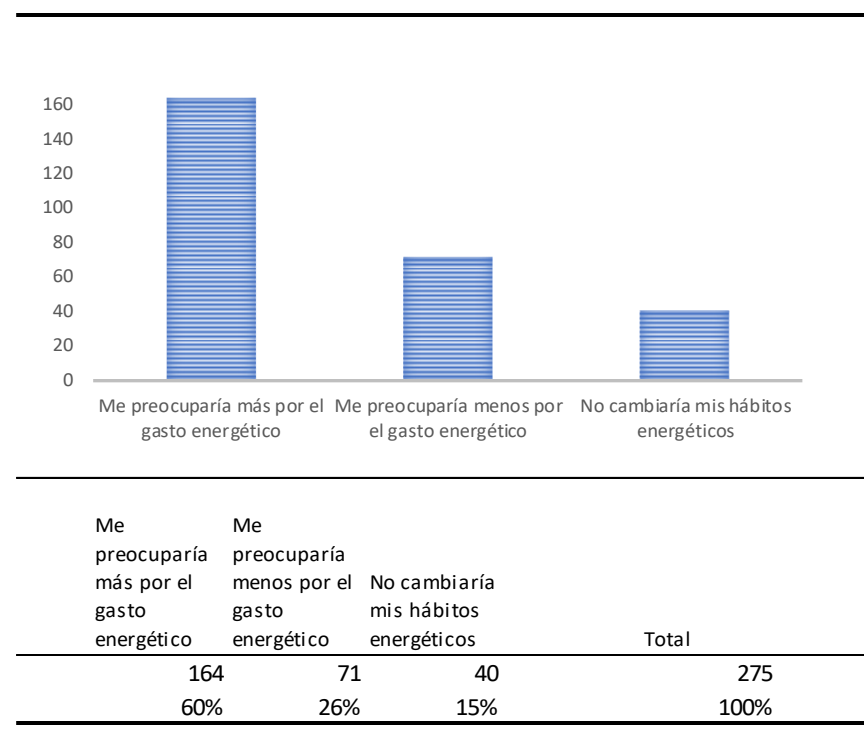

Fuente: Elaboración propia

Citación: APELLIDO, N. et al. Titulo completo del artículo. En: Libro de proceedings, CTV 2018. XII Congreso Internacional Ciudad y Territorio Virtual. "Ciudades y Territorios Inteligentes". UNCuyo, Mendoza, 5-7 septiembre 2018. Barcelona: CPSV, 2018, p. 263-284. 
Por otra parte, con el objeto de ponderar la importancia relativa que las personas le dan a la eficiencia energética, los encuestados fueron cuestionados sobre la prioridad que le darían a la realización de mejoras de tipo energético y no energético en la vivienda actual. En el primer grupo se incluyó la mejora del aislamiento en muros y ventanas y en el bóiler. En el segundo, en cambio, aspectos funcionales y estéticos, como es la remodelación de la cocina, los baños o el programa arquitectónico.

Como se ve, en la figura inferior, la importancia relativa de las mejoras de tipo energético es muy superior a las mejoras estéticas y funcionales. Estos resultados son coherentes con los hábitos energéticos anteriormente reportados, y ponen de relieve que la mejora de la eficiencia energética tiene recorrido incluso en los países que, como México, las prioridades se centran en la solución de problemas básicos como el acceso a la vivienda y la procuración de las condiciones de habitabilidad básicas.

\section{Tabla 6. Prioridades de mejora de la vivienda actual de los encuestados}

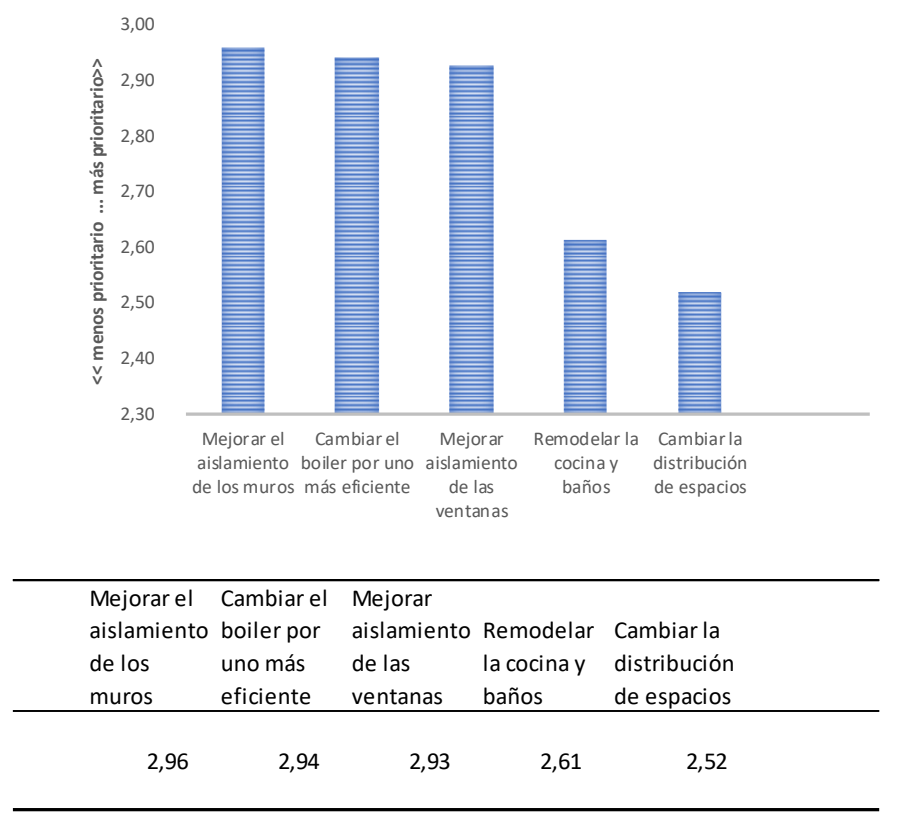

$4=$ prioridad alta, $1=$ prioridad baja

Fuente: Elaboración propia

Es probable que la incorrecta comprensión del significado de las etiquetas energéticas derive de la forma en cómo se expresan sus repercusiones económicas y ambientales. Por esa razón, se ha pedido a las personas que expresasen su preferencia por utilizar unidades técnicas versus otras de tipo ilustrativo. En la figura inferior se observa, con meridiana claridad, que los encuestados preferirían que el consumo energético de las viviendas estuviese representado en los pesos que la gente gasta en la factura energética (63\%), mientras que una menor parte está conforme con el uso de las unidades técnicas de mensuración de la energía.

Por lo que a las emisiones se refiere, de nuevo una minoría está de acuerdo con el uso de las unidades de masa, es decir, toneladas de dióxido de carbono; por el contrario, la mayor parte

Citación: APELLIDO, N. et al. Titulo completo del artículo. En: Libro de proceedings, CTV 2018. XII Congreso Internacional Ciudad y Territorio Virtual. "Ciudades y Territorios Inteligentes". UNCuyo, Mendoza, 5-7 septiembre 2018. Barcelona: CPSV, 2018, p. 263-284. 
(83\%) preferiría que dichas emisiones se expresasen en unidades ilustrativas, y particularmente las que se refieren a los árboles necesarios para compensarlas. Estos resultados representan que las políticas encaminadas a promover la eficiencia energética deben hacer una labor más enfocada a los aspectos "didácticos», en especial cuando los usuarios no tienen los recursos cognitivos para identificar correctamente las repercusiones derivadas tanto del consumo como de las emisiones.

\section{Tabla 7. Preferencias de los encuestados relativas al uso de las unidades en las que se deberían expresar en las etiquetas energéticas las repercusiones económicas y ambientales de la eficiencia energética}

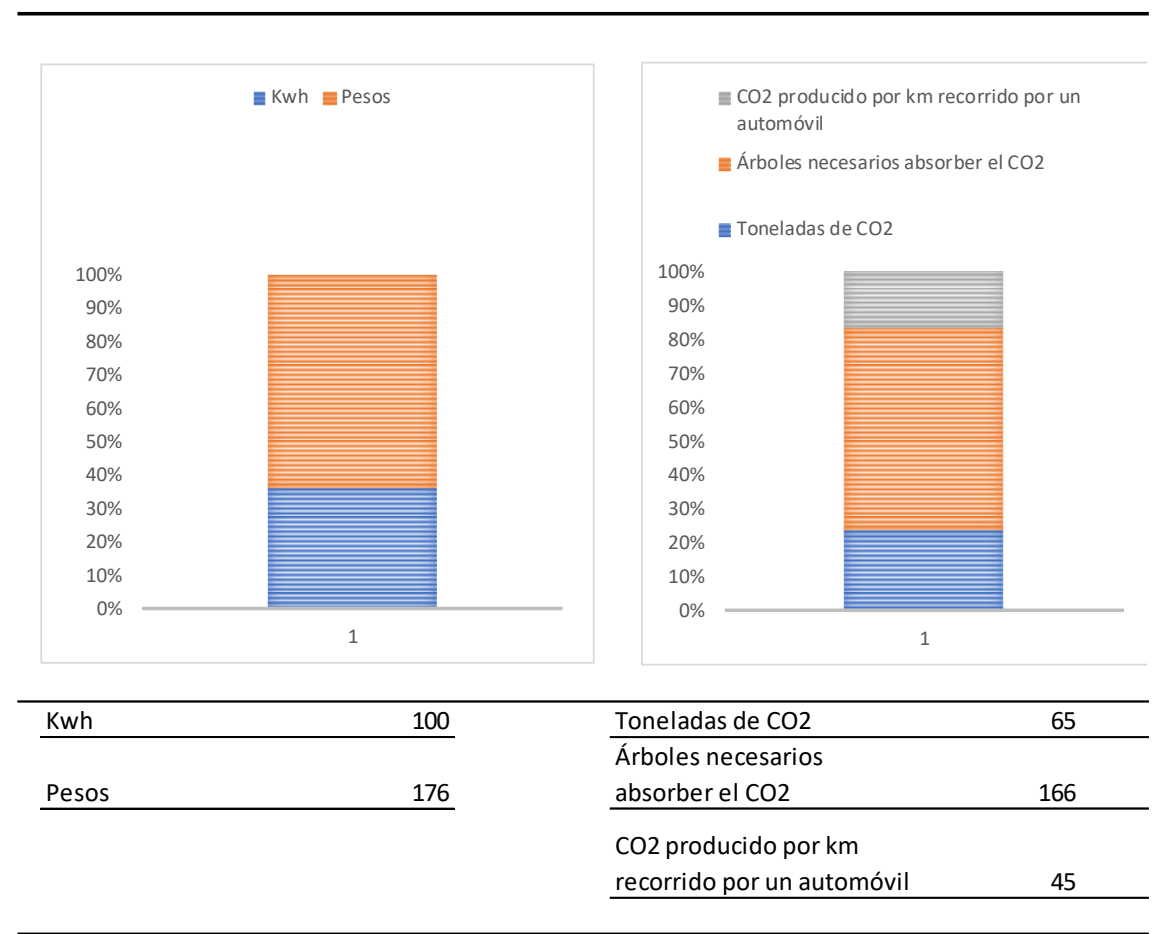

Fuente: Elaboración propia

\section{Disposición a pagar por una mejora en la eficiencia energética de la vivienda}

Finalmente, como se ha dicho en la metodología, se preguntó a las personas si estarían dispuestas a realizar un pago adicional en el alquiler o en la cuota mensual hipotecaria por acceder a un apartamento energéticamente más eficiente. Para ello, se informó que dicha vivienda significaría un ahorro en la factura de gas y electricidad equivalente a 600 pesos al mes, cifra que, siguiendo la metodología de la valoración contingente, sirve de valor de referencia y permite orientar a las personas sobre el valor a declarar.

La tabla inferior reporta los resultados. Como se ve, la mayor parte de los encuestados estaría dispuesta a hacer un pago adicional (92\%) en el alquiler o en la cuota mensual de su hipoteca, según alquilasen o comprasen el apartamento ofrecido. Como se ve, y es previsible, la mayor parte $(54 \%)$ de estas personas querría hacer un sobrepago inferior a los 600 pesos mensuales,

Citación: APELLIDO, N. et al. Titulo completo del artículo. En: Libro de proceedings, CTV 2018. XII Congreso Internacional Ciudad y Territorio Virtual. "Ciudades y Territorios Inteligentes". UNCuyo, Mendoza, 5-7 septiembre 2018. Barcelona: CPSV, 2018, p. 263-284. 
aunque la proporción dispuesta a pagar menos de 600 pesos/mes no es nada desdeñable (54\%), y en todo caso es muy superior al de las personas que no están dispuestas a pagar nada más.

\section{Tabla 8. Disposición a pagar adicional por alquilar o comprar (incremento en la cuota hipotecaria mensual) una vivienda energéticamente eficiente}

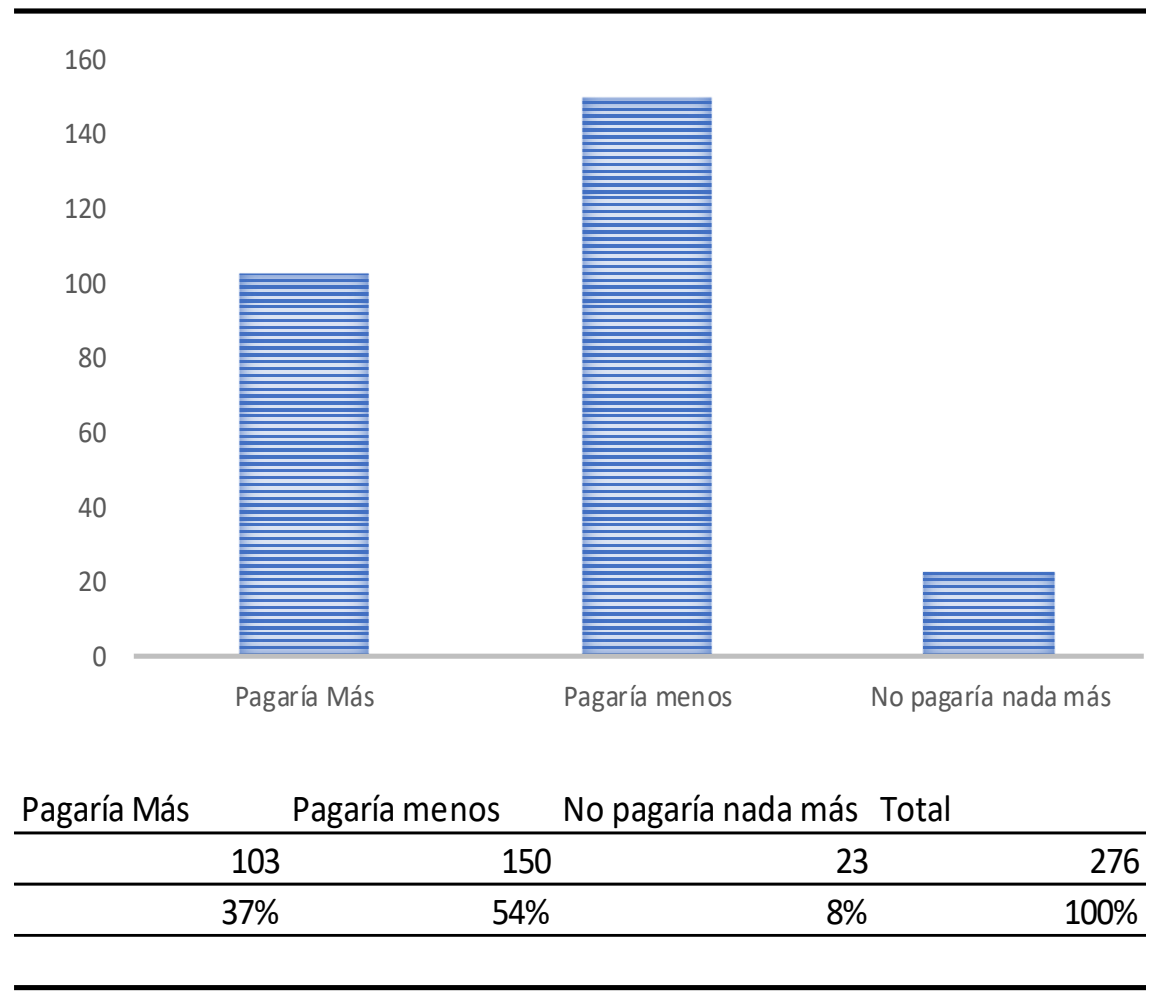

Fuente: Elaboración propia

A pesar de los esfuerzos, sólo 76 personas concretaron la cantidad exacta que estaban dispuestos a pagar, la cual se sitúa en 484 pesos (std. dv.=481.23); la amplia dispersión de estos datos obedece a que en su cómputo se han incluido los ceros verdaderos, es decir, la disposición a pagar nula por una mejora en la eficiencia energética. Para identificar dichos ceros verdaderos se han eliminado a las personas que no estaban dispuestas a pagar porque, a pesar de que querrían pagar, sus condiciones económicas no se lo permitían.

Se pidió a las personas que indicasen, dentro de un conjunto de opciones, las razones por las que estarían dispuestas a hacer un pago adicional. Según se observa en la tabla anterior, la mayor parte dijo que lo hacía o bien porque entiende que el ambiente se contamina menos o bien porque un ambiente más limpio mejora la salud de las personas.

Estos resultados ponen de relieve que, aunque de forma potencial o declarada, las personas en México tienen preocupaciones relacionadas con la preservación del ambiente y con la relación que hay entre ésta y la salud de las personas. En el caso concreto de Monterrey, estos hallazgos no son sorprendentes, puesto que se trata de la metrópoli más industrializada del país, cuyas manufacturas se han apoyado de forma histórica en la industria pesada. 


\section{Tabla 9. Razones por las que los encuestados están dispuestos a realizar un pago adicional por la vivienda eficiente}

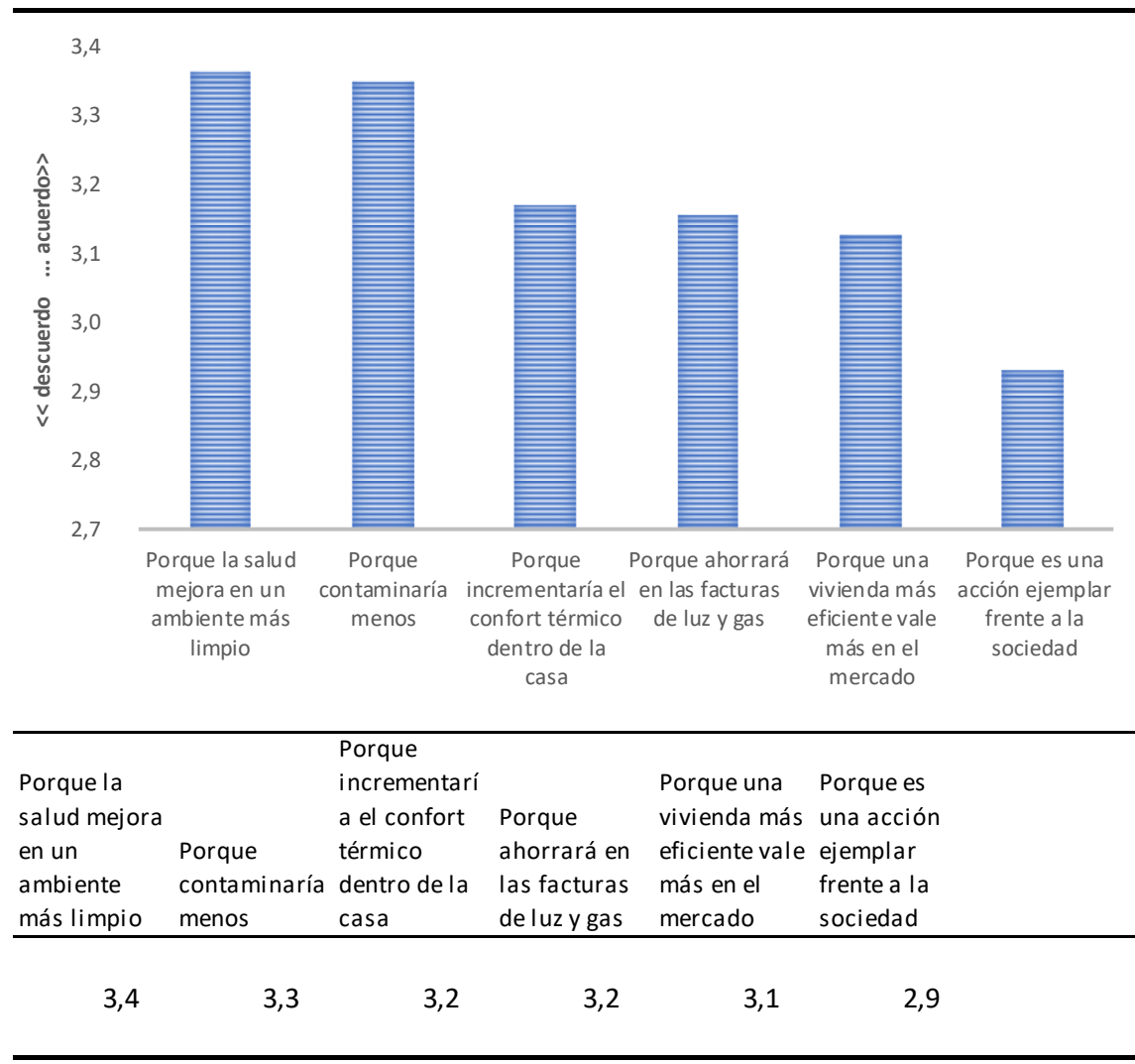

$4=$ muy de acuerdo, 1 = muy en desacuerdo

Fuente: Elaboración propia

\section{Discusión y conclusiones}

Al igual que Europa y Norteamérica, en América Latina la discusión acerca de la eficiencia energética en las edificaciones es un tema de gran actualidad y debate. Importantes esfuerzos se están realizando con tal de generar un esquema propio de certificación energética que se sumen a los existentes adaptados de otras geografías, como ha quedado de relieve en el desarrollo de este capítulo. Sin embargo, poco o nada se sabe sobre el efecto de la eficiencia energética sobre las preferencias de las personas, y más particularmente sobre la disposición a pagar por las viviendas más eficientes.

Este conocimiento reviste gran importancia, puesto que es bien sabido que la edificación eficiente con tecnologías pasivas o activas representa un coste de construcción superior a la construcción convencional, tanto porque las especificaciones técnicas son más exigentes, porque el volumen de la producción de los equipos es escaso y, por ende, no se aprovechan economías de escala y, además, al ser tecnologías nuevas, están todavía bajo la protección industrial de las patentes. Por tanto, es indispensable saber si las personas están dispuestas a pagar por una mejor eficiencia energética $y$, en definitiva, conocer si los desarrolladores inmobiliarios podrían compensar el sobrecoste constructivo. 
La investigación pretende analizar si los potenciales compradores de vivienda en Monterrey estarían dispuestos a pagar (DAP) más por viviendas energéticamente eficientes. Para ello, se acude a la valoración contingente en el marco de una encuesta más amplia que tiene por objeto conocer el nivel de conocimiento sobre las etiquetas energéticas, así como los hábitos medioambientales y la importancia relativa de las reformas energéticas.

Los resultados ponen de relieve que, a pesar de que cuantitativamente la gente dice conocer las etiquetas energéticas, en términos cualitativos confunde lo que miden. En efecto, parece que las personas creen que dichas etiquetas son indicadores de la calidad global de la vivienda y no sólo de lo que en realidad son: indicadores simplificados de la eficiencia energética. Pero más en el fondo aún parece que las personas no tienen claro el mismo concepto de eficiencia energética, es decir, el nivel de energía necesario para mantener la vivienda en condiciones de confort bajo un uso normal de la misma.

Todo junto, sugiere claramente que las políticas energéticas aplicadas al ámbito residencial deben hacer mayor esfuerzo por transmitir de forma didáctica el significado, tanto de la eficiencia energética, como de los elementos que subyacen en su cálculo. En ese mismo sentido, las personas declararon preferir que las etiquetas energéticas mostrasen las implicaciones económicas y ambientales mediante unidades fácilmente comprensibles, como el ahorro en pesos en la factura energética que se podría tener por acceder a una vivienda eficiente, o los árboles necesarios que permitirían compensar el CO2 emitido a la atmósfera. Es decir, es necesario avanzar a esquemas ilustrativos dirigidos a un público amplio conformado también por personas con una formación escasa, o bien con una formación no técnica.

El segundo objetivo consiste en saber si las unidades con las que se expresa la eficiencia energética inciden sobre la DAP. En ello, los resultados señalan que las personas están dispuestas a realizar un sobrepago adicional por la vivienda energéticamente más eficiente, si bien un poco menos que el ahorro en la factura de gas y electricidad que supondría dicha vivienda. Sólo el $8 \%$ de los encuestados dijo no estar dispuesto a pagar nada más, y de éstos una gran parte debido a que su economía familiar no podía permitirse gastar más en la vivienda, por más que ésta supusiese un ahorro potencial en la factura energética.

Sobre este extremo, es importante señalar que, en las personas de menos ingresos, que no suelen acudir a la climatización artificial por no podérselo permitir, la mejora en la eficiencia energética de la vivienda supone una mejora en el nivel de confort, pero también en las condiciones de salubridad y que, como la evidencia empírica lo señala, repercute en el estado de salud, especialmente en lo que a enfermedades respiratorias se refiere. Es decir, incluso en el evento de que la eficiencia energética no mejore las condiciones económicas de las personas, podría repercutir positivamente en el nivel de confort y sanidad de aquellas que se encuentran en lo que se ha llamado «pobreza energética».

En general, se observa que el mercado no es sensible a los beneficios que tiene una vivienda diseñada bioclimáticamente comparada con una que no tiene estas cualidades. Los consumidores buscan otro tipo de atributos antes de considerar el ahorro que representa tener eco tecnologías o un diseño ajustado al entorno. Los desarrolladores de fraccionamientos han usado mecanismos de subsidios por parte del gobierno federal lo cual faltaría evaluar la eficiencia energética.

Citación: APELLIDO, N. et al. Titulo completo del artículo. En: Libro de proceedings, CTV 2018. XII Congreso Internacional Ciudad y Territorio Virtual. "Ciudades y Territorios Inteligentes". UNCuyo, Mendoza, 5-7 septiembre 2018. Barcelona: CPSV, 2018, p. 263-284. 
Una línea que se abre para seguir investigado es introducir variables ambientales en el análisis de la valuación. Ya teniendo el costo-beneficio de los aspectos sustentables, se tienen que considerar las eco tecnologías obligatorias que marcan la CONAVI y SEDATU³. En la actualidad en Nuevo León, algunas inmobiliarias dan premio (más valor) al diseño sustentable de las viviendas, un $5 \%$ por el hecho de tener una orientación para crear eficiencia energética (por las condiciones climáticas de Monterrey), lo equivalente a una vivienda que se encuentra frente a parque.

En definitiva, según los resultados de nuestra investigación, parece haber en México un nicho de mercado interesado en la preservación del medio ambiente, que entiende que éste tiene repercusiones en la salud de las personas y, además, delante de un posible ahorro en la factura energética de su vivienda estaría dispuesto a pagar más por la misma en el evento de que ésta mejorase sus condiciones de eficiencia energética.

\section{Agradecimientos}

Este trabajo es producto del proyecto EnerVALOR «¿Cuánto nos importa la calificación energética? Un análisis del nivel de comprensión de los EPC, confianza percibida e impacto sobre las preferencias y valores residenciales», financiado por el Ministerio de Economía y Competitividad bajo la referencia BIA2015-63606-R (MINECO/FEDER).

Se agradece a los alumnos del Programa de Maestría en Valuación de la Facultad de Arquitectura de la UANL por su participación en el proceso metodológico: Alejandra Astorga, Jhoanakaren Contreras, Tania Dávila, Ana Soto, Hilda Navarro, Yammel Padilla, Natalia Silva, Ana Alemán, Damaris Javier, Jorge Pérez y Ana Vázquez.

\section{Referencias}

BURCHARD, J. E. (1965) Some Antidotes for Ugliness, A.I.A. Journal, Volumen XLIII (No. 4) pp. 29-34.

Comisión Nacional de Fomento a la Vivienda. Guía para el uso eficiente de la energía en la vivienda, 2006. Cd de México: MÉXICO. Recuperado de: www.conafovi.gob.mx

DE AYALA, A., I. Galarraga and J. Spardo (2016). The price of energy efficiency in the Spanish housing market, Energy Policy, 94.

DINAN, T.M. and J.A. Miranowski (1989). Estimating the implicit price of energy efficiency improvements in the residential housing market: a hedonic approach, Journal of Urban Economics, 1, vol. 25.

\footnotetext{
${ }^{3}$ como son: Aislamiento térmico en techo y muro de mayor superficie de insolación, el tipo de impermeabilización que se utiliza, sistemas de construcción que eviten los puentes térmicos (ej. losa con vigueta y bovedilla de poliestireno), incorporación de partesoles opacos, volados y/o ventanas remetidas en fachadas sur, este y oeste, la altura interior, paneles fotovoltaicos para el conjunto interconectados a red y el número de árboles que se cuenta por vivienda. 
EICHHOLTZ, P., K. Nils and J.M. Quigley (2010). Doing Well by Doing Good? Green Office Buildings, Program on housing and urban policy, Institute of Business and Economic Research, University of California, Berkeley, Working paper collection. April, 2010.

FITCH, J. M. (2002). Procedimiento para determinar el valor de la vivienda en el Área Metropolitana de Monterrey, Nuevo León, México: a partir del confort térmico. Tesis para obtener el Grado de Maestro en Valuación Inmobiliaria por la Universidad Autónoma de Nuevo León, México.

FITCH, J. M. (2017). Valuación ambiental e inmobiliaria de la vivienda. Monterrey: UANLLabýrinthos editores.

FITCH, J. M.; GARCIA, M. P. (2008): La incidencia de las externalidades ambientales en la formación espacial de valores inmobiliarios: el caso de la región metropolitana de Barcelona. En: Revista Arquitectura, Ciudad y Entorno: ACE, Año III, núm. 6. Obtenido desde: https://upcommons.upc.edu/handle/2099/4488

FUERST, F. and P. McAllister (2011a). The impact of energy performance certificates on the rental and capital values of commercial property assets. Energy Policy (39).

FUERST, F. and P. McAllister (2011b). Green noise and green value? Measuring the effects of environmental certification on office values. Real Estate Economics, 1, vol. 39.

FUERST, F., P. McAllister, A. Nanda and Wyatt Peter (2015). Does energy efficiency matter to home-buyers? An investigation of EPC ratings and transaction prices in England Energy Econ. January.

FUNDACIÓN IDEA (s/f). Eficiencia energética y ambiental en el sector vivienda. Revisión de prácticas nacionales e internacionales. Ciudad de México: Embajada Británica en México. $<$ http://fundacionidea.org.mx/assets/files/FIdea_libro\%20eficiencia\%20energetica\%20final.pdf>.

GARCíA, M. P. (1998). La valoració urbana sobre la base de les noves tecnologies de SIG. L'Exemple De L'Hospitalet De Llobregat. Tesis Doctoral UPC (Inédita).

GARCíA-HOOGHUIS, A. and Neila (2013). Transposición de las Directivas 2002/91/CE y 2010/31/UE en los Estados miembros de la UE y sus implicaciones, Informes de la Construcción, vol. 65. Nov., 2013.

HYLAND, M., R.C. Lyons and S. Lyons (2013). The value of domestic building energy efficiency-evidence from Ireland, Department of Economics. Working Paper 614, University of Oxford, SSRN: <http://dx.doi.org/10.2139/ssrn.2096296>.

KRUMM (1980) Neighborhood Amenities: An Economic Analysis. Source: RePEc. DOI: 10.1016/0094-1190(80)90017-0.

MARMOLEJO, C. (2016). La incidencia de la calificación energética sobre los valores residenciales: un análisis para el mercado plurifamiliar en Barcelona. Informes de la Construcción, vol. 68, julio-septiembre de 2016.

Citación: APELLIDO, N. et al. Titulo completo del artículo. En: Libro de proceedings, CTV 2018. XII Congreso Internacional Ciudad y Territorio Virtual. "Ciudades y Territorios Inteligentes". UNCuyo, Mendoza, 5-7 septiembre 2018. Barcelona: CPSV, 2018, p. 263-284. 
MARMOLEJO, C., M. Bravi (2017). Does the Energy Label (EL) Matter in the Residential Market? A Stated Preference Analysis in Barcelona. Buildings, 7(23).

Mejía D., Morillón D., Rodríguez L. (2001). Potencial estimado de ahorro y uso eficiente de energía en aires acondicionado mediante control solar en edificaciones, XXI Seminario Nacional sobre el uso racional de la energía y exposición de equipos y servicios. ATPAE Asociación de técnicos y profesionales en aplicación energética, A.C. México.

MILLER, N., J. Spiver and A. Florance (2008). Does Green pay off?, Final draft: 12 July 2008. $<w w w . u s g b c . o r g / S h o w F i l e . a s p x$ ?DocumentID=5537>.

MITCHELL, R.C., R.T. Carson (1989). Using Surveys to Value Public Goods: The Contingent Valuation Method. Resources for the Future. Washington, DC.

Morillón, G. D. (2005). Recomendaciones bioclimáticas para diseño arquitectónico y urbano: Estudios aplicables en Chihuahua, Cd. Juárez,Región Lagunera y Durango. México: CFEPAESE.

MUDGAL, S., L. Lyons and F. Cochen (2013). Energy performance certificates in buildings and their impact on transaction prices and rents in selected EU countries. Bio Intelligence Service. Working paper, april, 2013.

PONTUS, C., G. Hassel Lars and N. Semenova (2014). Energy Performance and Housing Prices, Sustainable Development). Working paper collection, May, 2014.

RIERA, P. (1994). Manual de Valoración Contingente. Madrid: Instituto de Estudios Fiscales.

ROCA, J. (1988). La estructura de valores residenciales un análisis teórico y empírico. Madrid: Instituto de Estudios de Administración Local.

SALVI, M., A. Horehájová and J. Neeser (2010). Der Nachhaltigkeit von Immobilien einen finanziellen Wert geben- Der Minergie- Boom unter der Lupe. University of Zurich, Center for Corporate Responsibility and Sustainability, March 2010.

SECRETARÍA de Energía (2011). NORMA Oficial Mexicana NOM-020-ENER-2011, Eficiencia energética en edificaciones. Envolvente de edificios para uso habitacional. Diario Oficial, martes 9 de agosto de 2011.

SECRETARÍA de Energía (2016). Resolución por la que se modifican los valores de coeficiente global de transferencia de calor $(K)$ de la tabla 1 , se agregan definiciones y se acota la verificación de la Norma Oficial Mexicana NOM-020-ENER-2011, Eficiencia energética en edificaciones-Envolvente de edificios para uso habitacional, publicada el 9 de agosto de 2011. Diario Oficial, martes 4 de octubre de 2016.

SHEINBAUM, C. (1996). Tendencias y perspectivas de la energía residencial en México: Análisis comparativo con las experiencias de conservación y eficiencia de los países de la OCDE. México: PUE-UNAM.

SOGUEL Nils, C. (1996). Contingent Valuation of Traffic Noise Reduction Benefits. Swiss Journal of Economics and $S$

Citación: APELLIDO, N. et al. Titulo completo del artículo. En: Libro de proceedings, CTV 2018. XII Congreso Internacional Ciudad y Territorio Virtual. "Ciudades y Territorios Inteligentes". UNCuyo, Mendoza, 5-7 septiembre 2018. Barcelona: CPSV, 2018, p. 263-284. 